\title{
Sistem Pembayaran Elektronik pada Transportasi Angkutan Kota menggunakan Rotary Encoder
}

\author{
THETA DINNARWATY PUTRI, WINARNO SUGENG, \\ FUADI RAMDANI
}

Program Studi Informatika Institut Teknologi Nasional Bandung, Indonesia
Email: theta@itenas.ac.id

Received 2 Februari 2021 | Revised 12 Maret 2021 | Accepted 27 April 2021

\begin{abstract}
ABSTRAK
Angkutan kota (angkot) adalah salah satu transportasi umum yang berada di kota Bandung. Tetapi belum semua warga menggunakannya karena tarif yang diberikan pengemudi tidak sesuai jarak yang ditempuh dan menyebabkan tarif yang beragam. Tujuan dari penelitian ini adalah membuat sistem pembayaran pada angkot serta menentukan tarifnya sesuai jarak yang ditempuh. Penelitian ini memodelkan sistem pembayaran menggunakan RFID, rotary encoder dan arduiono uno. Sistem yang dibuat menghasilkan output berupa tarif sesuai jarak yang ditempuh dengan menghitung jumlah putaran roda yang dihubungkan dengan rotary encoder. Rotary encoder digunakan untuk mengetahui arah putaran roda yang mana dapat menghasilkan output berupa jarak. Hasil dari penelitian ini adalah jarak yang diperoleh dari putaran roda yang di ekuivalensikan dengan jarak sebenarnya, dimana tarif dasar sebesar Rp.2000 akan bertambah Rp.100 setiap bertambah jarak $100 \mathrm{~m}$.
\end{abstract}

Kata kunci: Rotary Encoder, RFID, Transportasi, Arduino

\begin{abstract}
City transportation (angkot) is one of the public transportation located in the city of Bandung. However, not all residents use it because the tariff given by the driver does not match the distance traveled and causes varying rates. The purpose of this research is to create a payment system for public transportation and determine the tariff according to the distance traveled. This study models a payment system using RFID, rotary encoder and Arduiono Uno. The system created produces an output in the form of a rate according to the distance traveled by calculating the number of wheel rotations connected to the rotary encoder. Rotary encoder is used to determine the direction of rotation of the wheel which can produce output in the form of distance. The result of this research is the distance obtained from the rotation of the wheel which is equivalent to the actual distance, where the basic fare of Rp. 2000 will increase by Rp. 100 for every $100 \mathrm{~m}$ increase in distance.
\end{abstract}

Keywords: Rotary Encoder, RFID, Transportation, Arduino 
Putri, dkk

\section{PENDAHULUAN}

Angkutan kota (angkot) adalah salah satu transportasi umum yang sering digunakan oleh warga di kota Bandung. Tetapi masih banyak warga yang tidak menggunakan transportasi umum tersebut (Djahi, Doo, \& Nuga, 2019). Hal ini karena layanan yang diberikan belum memuaskan, mulai dari kondisi angkutan kota, tingkat kriminalitas, minimnya tingkat kedisiplinan pengemudi sampai masalah tarif (Jauhariah, Virgono, \& Sunarya, 2016). Untuk naik dan turun di tempat yang sama pengemudi angkot terkadang dalam hal pembayarannya memberikan tarif yang berbeda.

Setiap hari, minggu atau bulannya, pengemudi angkot harus menyerahkan setoran kepada pemilik angkot sesuai dengan kesepakatan yang telah disepakati bersama di awal (Kuswidiyanto, 2018). Sistem kejar setoran yang dibebankan oleh pemilik angkot kepada pengemudi juga terkadang membuat pengemudi angkot menaikkan tarif agar dapat mengejar setoran setiap harinya (Saputra, Pambudi, \& Subagjo, 2016). Untuk jarak yang sama, tak jarang jika menaiki angkot yang lain pembayarannya sering kali tidak sesuai jarak yang ditempuh oleh seorang penumpang dan menyebabkan pembayaran yang berbeda (Utomo, Utomo, \& Yohanes, 2016). Penumpang yang biasanya membayar dengan tarif tertentu dapat diminta untuk membayar lebih (Wiharja \& Herlambang, 2019). Sebaliknya, supir yang biasa mendapatkan sejumlah uang bisa mendapatkan jumlah yang kurang dan langsung ditinggalkan penumpang.

Layanan dari angkot perlu diperbaiki agar masyarakat menjadi lebih memilih menggunakan angkot. Salah satu caranya adalah dengan memperbaiki sistem pembayaran angkot yang selama ini juga masih menimbulkan kerugian, baik bagi penumpang maupun pengemudi angkot (Raj, 2018). Karena itu dibuatlah sistem pembayaran alternatif dengan menggunakan sistem pembayaran elektronik (Ardiansyah \& Rohman, 2019), agar setiap warga di Kota Bandung dapat membayar sesuai jarak yang ditempuh oleh masing - masing warga saat menggunakan angkot. Dalam memodelkan sistem pembayaran elektronik digunakan RFID (Olla, 2016), rotary encoder dan arduino uno. Dimana rotary encoder digunakan untuk mengetahui arah putaran roda untuk menghasilkan output berupa jarak (Dejan, 2016), sehingga tarif yang keluar sesuai dengan jarak tempuh yang dilalui angkot.

Berdasarkan permasalahan pada penelitian terdahulu yaitu pembayaran yang diminta oleh pengemudi angkot sering kali berbeda dengan jarak yang ditempuh oleh seorang penumpang (Hansamu, 2015) sehingga dibuatlah sistem pembayaran alternatif dengan menggunakan sistem pembayaran elektronik (Khirani, 2015). Atas permasalahan tersebut, maka dibangun sistem pembayaran alternatif dengan menggunakan pembayaran elektronik pada transportasi angkot sesuai jarak yang ditempuh menggunakan rotary encoder dimana rotary encoder tersebut digunakan untuk mengetahui arah putaran roda yang mana dapat menghasilkan output berupa jarak, sehingga tarif yang keluar sesuai dengan jarak tempuh yang dilalui angkot.

\section{METODE PENELITIAN}

Metode proses pembuatan sistem dalam penelitian ini menggunakan model prototype. Penelitian ini menggunakan 3 modul hardware yaitu RFID-RC522, Rotary Encoder, Arduino Uno, software yang digunakan Arduino IDE. Modul RFID terdiri dari RFID tag dan RFID reader, modul rotary encoder terdiri rotary encoder $k y-040$. RFID tag memiliki ID yang discanning pada $R F I D$ reader dengan cara mengirimkan gelombang radio yang dikirimkan 
antena dari $R F I D$ reader dan membuat $R F I D$ tag aktif untuk mengirimkan informasi berupa $I D$. Sistem yang akan dibuat menghasilkan output berupa tarif sesuai jarak yang ditempuh dengan menghitung jumlah putaran roda yang dihasilkan oleh rotary encoder ky-040. Dimana rotary encoder memiliki 2 logika output 0 dan 1, logika tersebut menghasilkan sinyal kotak yang memiliki beda phasa 90 derajat untuk mengetahui arah putaran. Pada sistem terdapat roda yang berputar kearah putaran yang dihasilkan rotary encoder $k y-040$. Jumlah putaran roda diperoleh ketika posisi roda kembali ke posisi semula, jumlah putaran roda dan $I D$ yang didapatkan dari RFID tag tersebut diproses menggunakan perhitungan jumlah putaran roda yang diperoleh dikalikan dengan pi $(\pi)$ dan diameter roda, yang diprogram pada arduino uno untuk menghasilkan jarak yang ditempuh, jarak kemudian dikonversikan dengan tarif untuk menghasilkan tarif sesuai jarak yang ditempuh.

Pada tahap ini menjelaskan mengenai ide dasar tentang posisi awal (P1) dari sebuah ban yang berputar berlawanan arah jarum jam (counter clockwise) menuju kembali ke posisi awal pada saat berputar pertama kalinya, dimana posisi pergerakan ban dari posisi awal untuk kembali pada posisinya semula itu disebut (P2). Pergerakan ban dari posisi awal (P1) menuju posisinya semulanya (P2) dapat menghasilkan sebuah jarak (D1). Jarak pertama (D1) yang ditempuh oleh suatu ban merupakan posisi awal (P1) menuju ke posisi semula (P2) pada putaran ban pertama. Untuk jarak kedua (D2) selanjutnya dapat dihasilkan melalui posisi awal (P2) pada saat berputar kedua kalinya menuju posisi semula (P3) dan seterusnya untuk jarak yang selanjutnya. Jarak total (Dt) merupakan penjumlahan dari jarak pertama (D1) ditambah jarak kedua (D2) sampai dengan jarak seterusnya (Dn).

Jarak pertama (D1) menuju jarak kedua (D2) menghasilkan sebuah tarif pertama (Rp1) dan untuk selanjutnya jarak kedua (D2) menuju jarak ketiga (D3) menghasilkan sebuah tarif yang kedua (Rp2) dan seterusnya untuk menghasilkan tarif yang selanjutnya. Tarif total (Rp t) merupakan penjumlahan dari tarif pertama (Rp1) ditambah dengan tarif kedua (Rp2) sampai dengan tarif seterusnya ( $\mathrm{Rp} n$ ) yang dihasilkan oleh jarak, konsep ide dasar tersebut dapat terlihat pada Gambar 1.

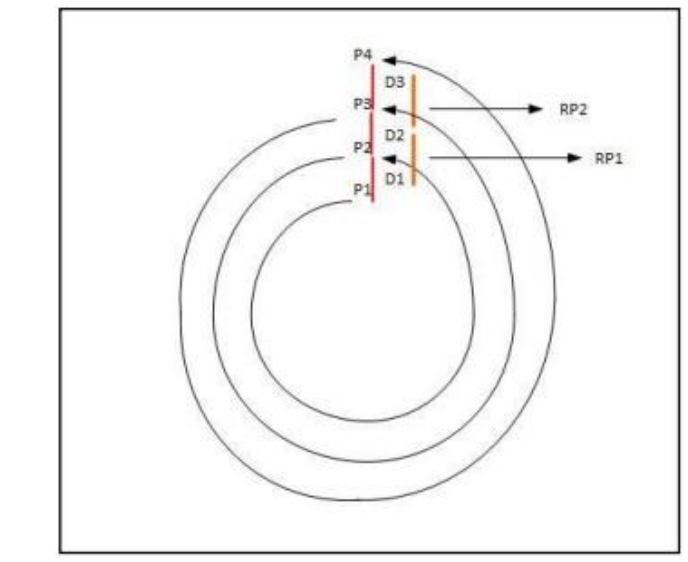

\section{Gambar 1. Konsep Dasar Perhitungan Jarak}

Perancangan sistem keseluruhan dalam penelitian sistem pembayaran elektonik pada transportasi angkutan kota ini terdapat beberapa proses bisnis dan alur yang terdapat pada Gambar 2 berikut.

Supir angkot mendaftarkan pada bagian pengelola agar terdaftar dan dapat menggunakan sistem pembayaran. Bagian pengelola memasukkan data - data dari pengemudi untuk dimasukkan kedalam sistem. Supir angkot mendapatkan alat yang digunakan untuk 
terhubung pada sistem dan beberapa kartu member yang sudah terisi saldo untuk langsung dapat diserahkan kepada penumpang jika belum melakukan registrasi.

Penumpang yang tidak memiliki kartu member diharuskan untuk mendaftar pada bagian pengelola untuk dapat menjadi member atau penumpang dapat langsung untuk melakukan registrasi dengan meminta pada supir angkot karena supir angkot memiliki beberapa persediaan kartu member. Bila melakukan registrasi pada bagian pengelola, bagian pengelola akan memasukkan data - data dari penumpang ke dalam sistem, jika melakukan registrasi langsung di angkot supir angkot akan memberikan kartu member Setelah melakukan registrasi penumpang mendapatkan kartu member yang digunakan untuk melakukan pembayaran pada angkot dengan melakukan tapping pertama sistem akan membaca kartu penumpang kemudian setelah berjalan akan mengkalkulasikan jarak yang didapat. Pada saat turun penumpang diharuskan melakukan tapping kedua dan saldo dari penumpang yang terdapat pada kartu berkurang sesuai jarak yang ditempuh.

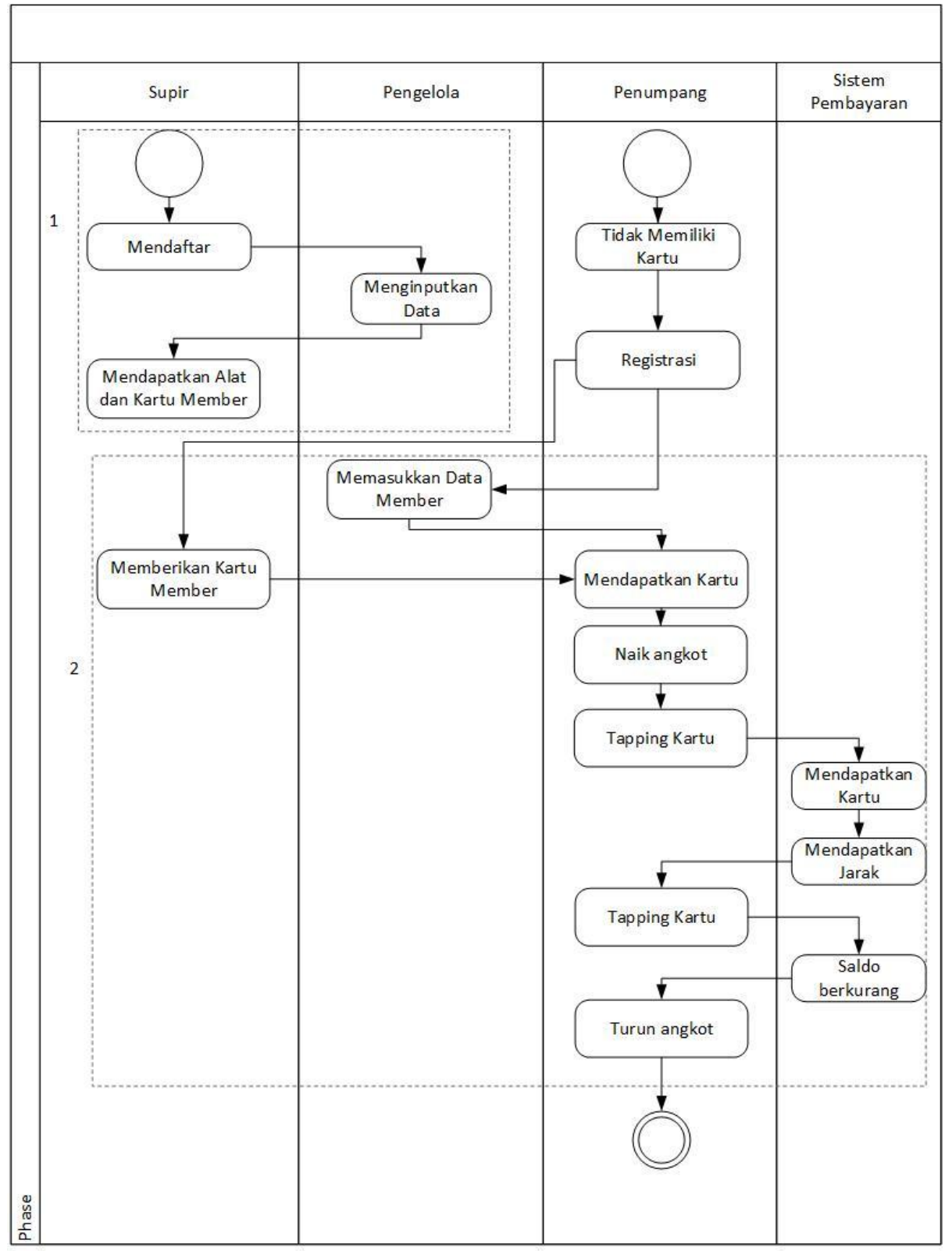

Gambar 2. Proses Bisnis Sistem Pembayaran Elektronik 
Gambar 3 merupakan workflow pengunaan sistem di dalam angkot dimana untuk penggunaan dimulai ketika penumpang menaiki angkot untuk melakukan tapping RFID tag pada RFID reader. Pada saat sebelum tapping diharuskan menekan tombol, dan setelah melakukan tapping statusnya berubah menjadi naik, ketika status berubah membuat rotary encoder aktif yang dihubungkan dengan sebuah roda untuk melakukan perhitungan jarak dengan memanfaatkan putaran roda. Ketika berhenti penumpang diharuskan menekan tombol sekali lagi dan saat tapping kedua kalinya dengan menggunakan RFID tag pada RFID reader status penumpang berubah menjadi turun membuat rotary encoder berhenti. Dengan menggunakan rumus perhitungan jarak dan memanfaatkan putaran roda jarak dapat diperoleh untuk kemudian dikonversikan menjadi tarif yang dipotong dari jumlah saldo pengguna dan menampilkannya pada layar $L C D$. Jika saldo penumpang dibawah minimal maka diharuskan melakukan top saldo terlebih dahulu.

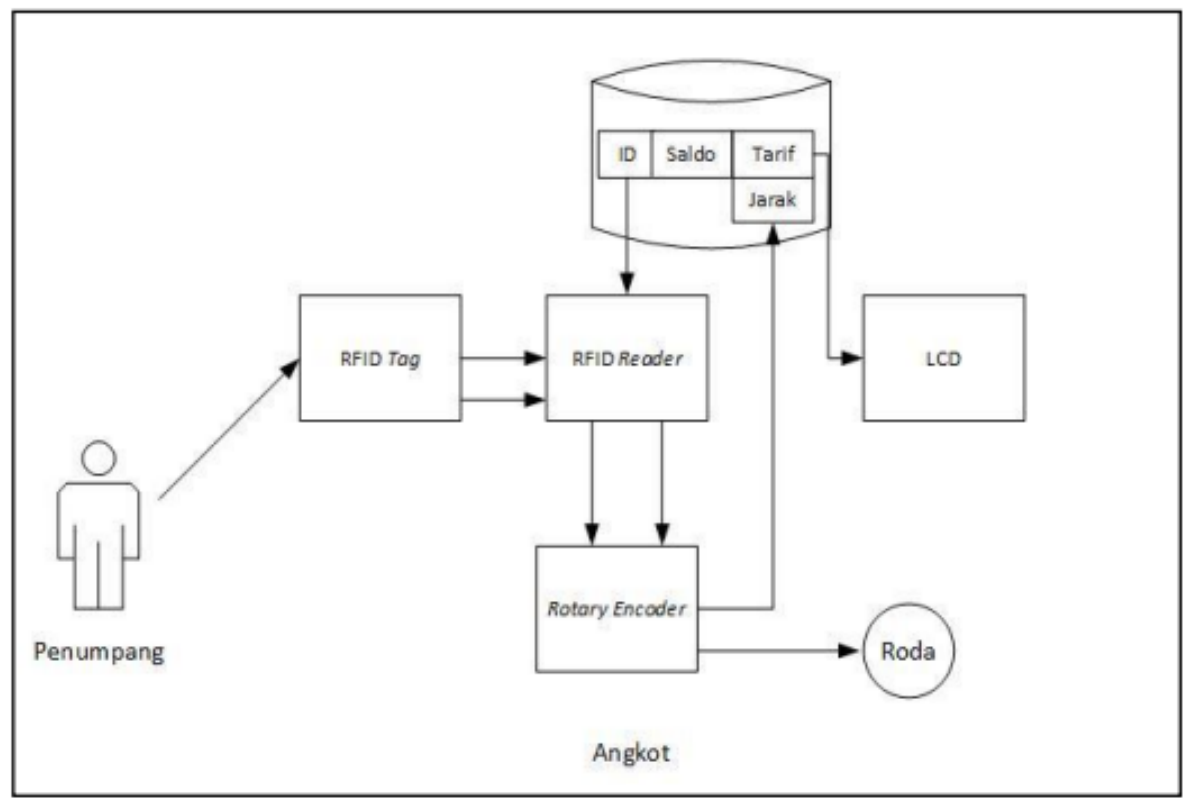

Gambar 3. Workflow Penggunaan Sistem di Dalam Angkot

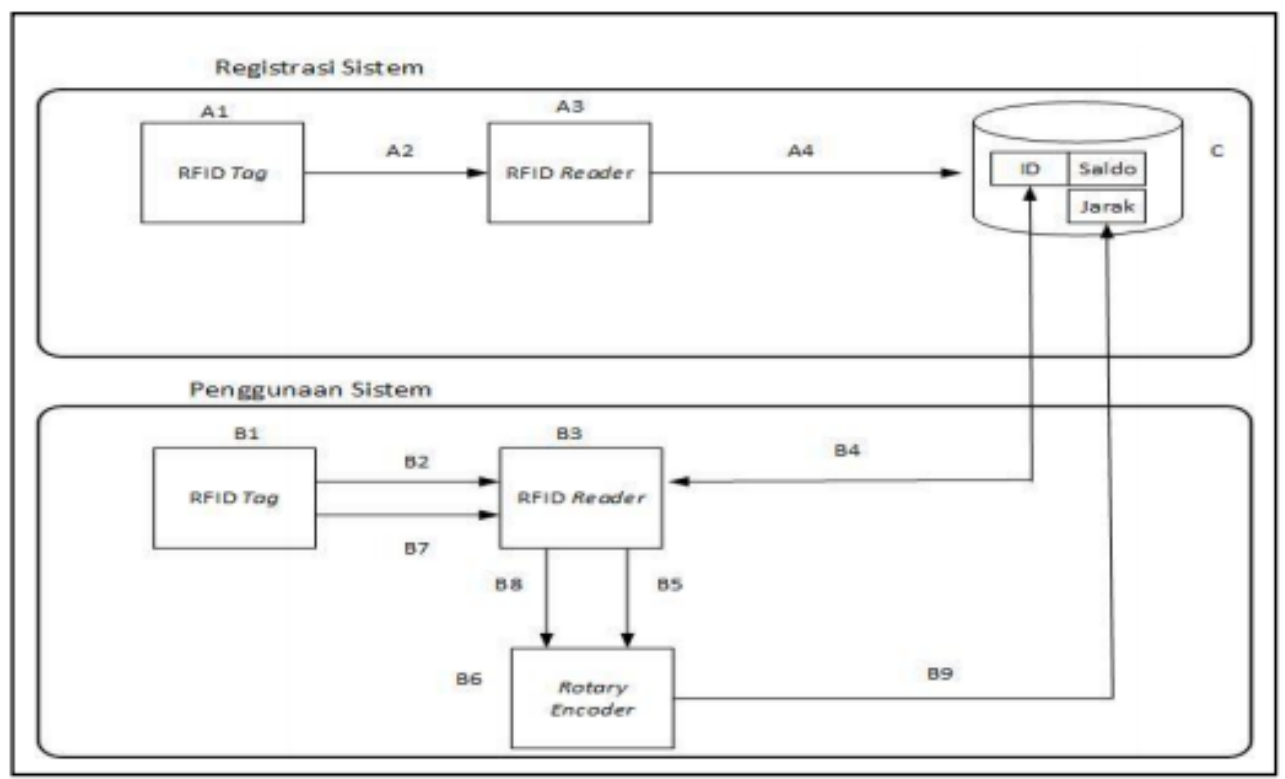

Gambar 4. Blok Diagram Sistem Pembayaran Elektronik Angkutan Kota 
Perancangan dalam penelitian rancang bangun sistem pembayaran elektonik pada transportasi angkutan kota memiliki 2 sistem yaitu terdapat registrasi sistem dan penggunaan sistem. Berikut adalah penjelasan blok diagram yang ditujukan pada Gambar 4.

Pada registrasi sistem terdapat perangkat yang digunakan untuk melakukan registrasi agar penumpang menjadi member dan dapat menggunakan sistem ini yaitu melalui $R F I D$ tag yang memiliki no id (A1) dan dilakukan tap agar id yang terdapat paada RFID tag dapat terbaca (A2) oleh RFID reader (A3) dimana RFID tag mengirimkan gelombang radio agar $R F I D$ tag dapat aktif dan mengirimkan informasi berupa no id yang dapat terbaca oleh $R F I D$ Reader.(A4) Saldo dan id dapat dikirim pada database (C) dimana saldo diinputkan secara manual agar tersimpan pada sistem tersebut.

Pada penggunaan sistem pengguna melakukan tap pertama kali dengan menggunakan $R F I D$ tag (B1) yang memiliki no id untuk mengirimkan gelombang radio (B2) agar no id dapat dibaca oleh $R F I D$ reader (B3) dan melakukan update terhadap id yang ditapkan sesuai RFID tag (B4) dialam database (C). Setelah ditapkan pertama kalinya (B5) rotary encoder dapat aktif untuk melakukan pergerakan dan melakukan perhitungan agar menghasilkan jarak yang ditempuh (B6). Pada saat RFID tag (B7) ditapkan untuk kedua kalinya rotary encoder berhenti melakukan perhitungan jarak (B8), jarak yang didapatkan (B9) mengurangi saldo dari pengguna yang terdapat dalam database (C).

Alur dari flowchart keseluruhan yang terdapat pada Gambar 5 diuraikan sebagai berikut. Pada saat memulai terdapat tombol naik yang digunakan untuk mengubah status penumpang menjadi naik pada sistem jika tombol naik tidak ditekan sistem tidak dapat berjalan dan jika tombol turun yang ditekan sistem selesai dikarenakan terjadi error. Ketika tombol naik ditekan status penumpang yang terdapat pada database berubah menjadi naik atau bernilai 1 , untuk dapat menjalankan sistem yang selanjutnya. Sistem bekerja pada subproses RFID dimana pada subproses ini melakukan cek kondisi registrasi penumpang yang terdapat pada database. Pada proses ini dicek apakah saldo dari penumpang kurang dari batas minimal yang telah ditentukan. Jika saldo penumpang kurang diharuskan dilakukan top up saldo untuk menambahkan saldo, agar saldo penumpang minimal dari batas yang telah ditentukan dan kembali pada proses awal (1). Jika saldo mencukupi yang terdapat pada database proses selanjutnya adalah melakukan transaksi elektronik dimana pada proses ini rotary encoder yang sudah dimodifikasi dengan sebuah roda akan dihitung jumlah putarannya dan diolah menggunakan rumus keliling lingkaran yang diprogram pada arduino untuk menghasilkan jarak yang dan tarif sesuai jarak.

Alur dari flowchart subproses RFID yang terdapat pada Gambar 6 diuraikan sebagai berikut. Pada subproses RFID memperlihatkan status registrasi dari penumpang yang menggunakan sistem ini yang terdapat pada database. RFID tag ditapkan pada RFID reader agar status registrasi penumpang yang terdapat pada database dapat terbaca oleh $R F I D$ reader dengan cara RIFD reader mengirimkan gelombang radio dan membuat RFID tag aktif. RFID reader dapat membaca status registrasi dari penumpang yang terdapat pada database setalah meneruskan inforamasi yang terdapat $R F I D$ tag, RFID reader mengirimkan gelombang radio dan membuat RFID tag aktif dan untuk mendapatkan informasi dari RFID tag. Pada proses ini dilakukan pengecekan apakah status registrasi dari penumpang terdapat pada database atau tidak. Jika status registrasi dari penumpang terdaftar pada database sistem melakukan update pada database dari status penumpang (6) jika status reigstrasi tidak ada penumpang belum melakukan pendaftaran. 


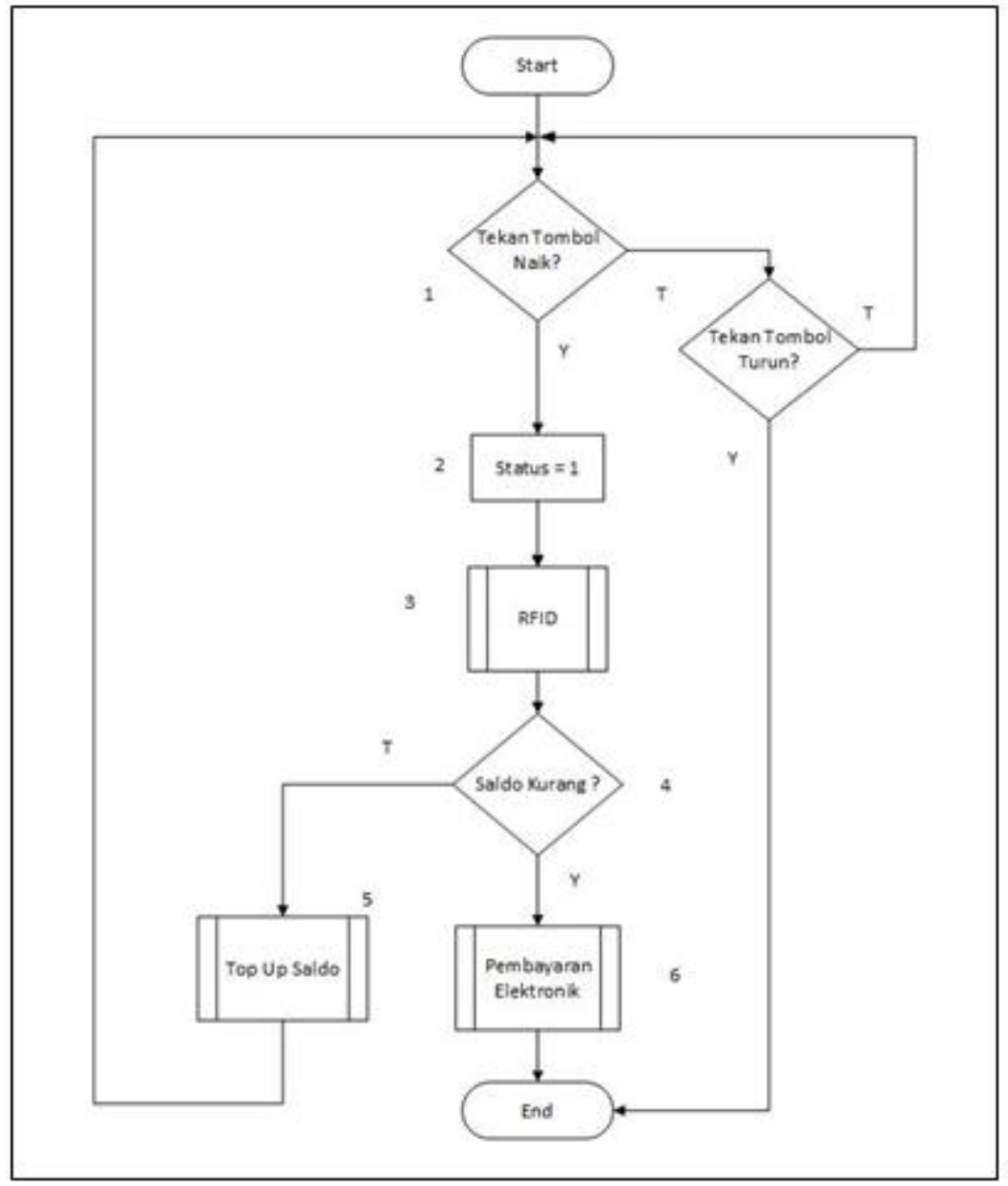

Gambar 5. Flowchart Sistem Keseluruhan Pembayaran Elektronik Angkutan Kota

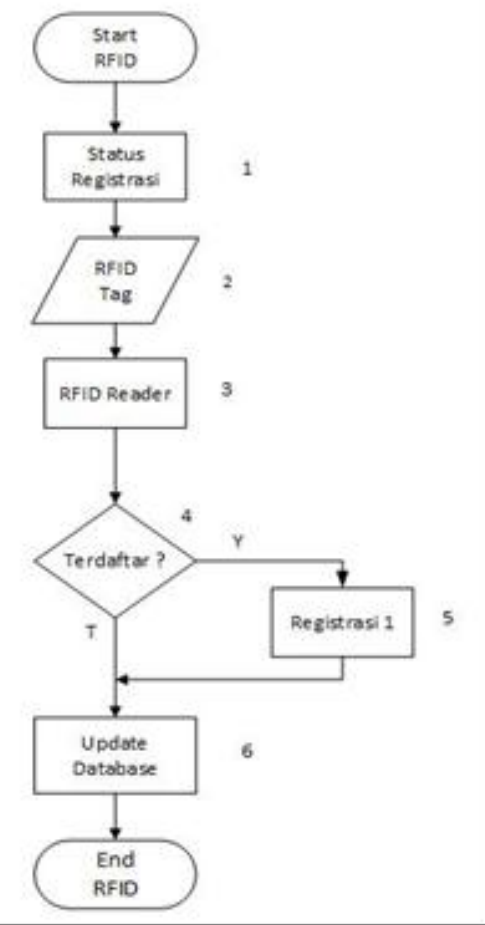

Gambar 6. Sub Flowchart Sistem RFID

MIND - 7 
Alur dari flowchart subproses top up yang terdapat pada Gambar 7 diuraikan sebagai berikut. Pada subproses top up saldo terdapat pada aplikasi lain dimana nama dan saldo dari penumpang diinputkan pada sebuah aplikasi. Setelah nama dan saldo diinputkan RFID tag ditap pada $R F I D$ reader agar id yang terdapat pada $R F I D$ tag dapat terbaca oleh $R F I D$ reader. $R F I D$ reader dapat membaca no id yang terdapat pada $R F I D$ tag dengan cara $R F I D$ reader mengirimkan gelombang radio dan membuat RFID tag aktif dan meneruskan informasi yang terdapat pada RFID tag. Nama, saldo dan id akan tersimpan dalam database setalah diinputkan pada aplikasi dan RFID tag yang ditapkan pada RFID reader dan membuat saldo dari pengguna menjadi bertambah.

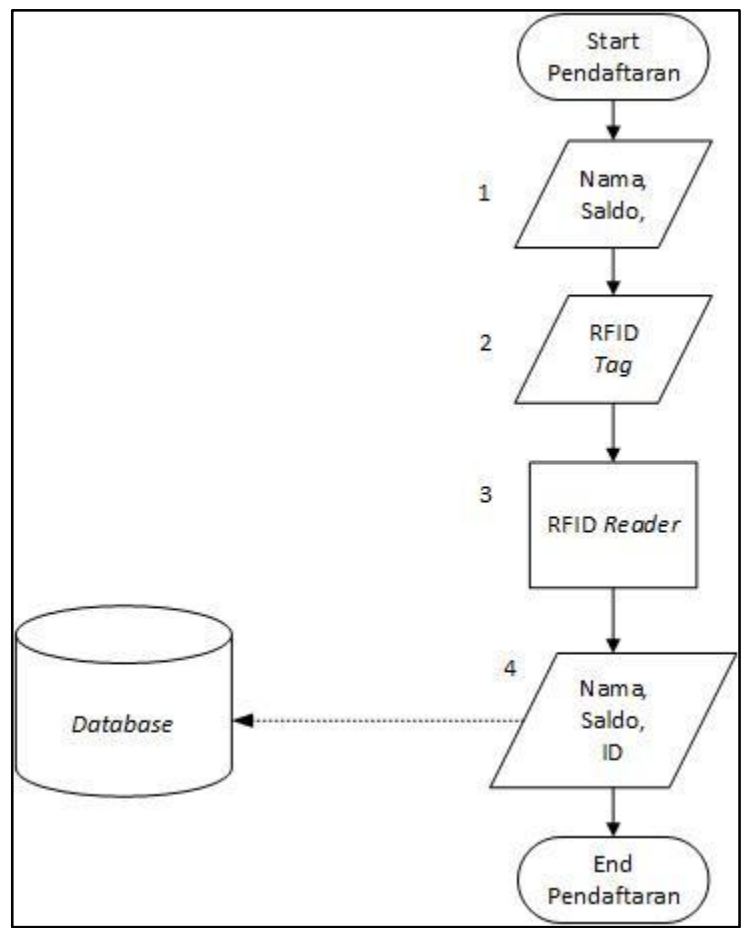

Gambar 7. Sub Flowchart Top Up Saldo

Alur dari flowchart subproses pembayaran elektronik yang terdapat pada Gambar 8 diuraikan sebagai berikut:

1. Pada proses ini dimulai inisialisasi variabel yang digunakan dalam subproses pembayaran elektronik, yaitu :

$\Pi=22 / 7$

$\mathrm{d}=2$

Tarif Dasar $=$ Rp 2000

Jarak Minimum $=2000$

Jarak Lebih $=0$

Pulsa $=100$

Jarak Hitung $=100$

2. Proses perhitungan rumus awal:

$$
\begin{aligned}
& \mathrm{F}=\pi \mathrm{xd} \\
& \mathrm{K}=\text { Pulsa } / \mathrm{F}
\end{aligned}
$$

3. Rotary encoder digunakan untuk menghitung jumlah putaran roda pada sistem yang bekerja dengan memanfaatkan 2 channel output A (CLK) dan B (DT) untuk menggerakkan roda yang memiliki logika output 0 dan 1 , dimana logika tersebut digunakan untuk mengetahui arah putaran dari roda apakah searah jarum jam (Clockwise) yang memiliki output berbeda $A=1$ dan $B=0$ dan selalu bergantian tiap 
gerakan menjadi $A=0$ dan $B=1$ dan setersunya jika digerakan kembali lagi ke awal output dari channel $\mathrm{A}=1$ dan $\mathrm{B}=0$, atau berlawan jarum jam (Counter Clockwise) yang memiliki output $A=0$ dan $B=0$ dan selalu bergantian tiap gerakan menjadi $A=1$ dan $B=1$ dan seterusnya kembali ke awal yaitu $A=0$ dan $B=0$ ketika digerakkan.

4. Pada tahap ini dilakukan beberapa proses yaitu inisialisai variabel $P=0$ dan $\mathrm{N}=0$, dimana $\mathrm{P}$ merupakan jumlah putaran roda yang dihasilkan dalam sistem, $\mathrm{N}$ merupakan jumlah pergerakan roda yang dibutuhkan untuk kembali ke titik semula saat rotary encoder bergerak 1 posisi, Posisi roda $(\mathrm{N})$ selalu bertambah 1 dan Ketika $\mathrm{N}>=30$ menghasilkan 1 putaran atau $\mathrm{P}=\mathrm{P}+1$ dan seterusnya jika $\mathrm{N}$ kembali bergerak $>=30$.

5. Pada proses ini terdapat kondisi dimana tombol turun ditekan atau tidak sebelum tombol turun ditekan rotary akan terus bergerak dan melakukan pergerak pada ban untuk mendapatkan jumlah putaran.

6. Pada saat tombol turun ditekan akan melakukan perhitungan rumus jarak yaitu

$$
\begin{gathered}
\text { Jarak }=\mathrm{F} \times \mathrm{P} \times \mathrm{K} \\
\mathrm{F}=\mathrm{n} \times \mathrm{d} \\
\mathrm{K}=\text { Pulsa } / \mathrm{F}
\end{gathered}
$$

7. Saldo dari penumpang yang teradapat pada database akan dikurangi tarif dengan ketentuan sebagai berikut:

jarak $<=2000=$ Rp. 2000

jarak $>2000$ dan $<2100=$ Rp. 2000

jarak $>=2100$ dan $<2200=$ Rp. 2100

jarak $>=2200$ dan $<2300=$ Rp. 2200

dan seterusnya untuk kelipatan jarak 100 tarif bertambah Rp.100

8. Pada proses ini dilakukan cek kondisi apakah jarak yang dihasilkan melebihi atau sama dengan jarak minimum yang ditentukan jika kurang dari jarak minimum atau sama dengan jarak minimum saldo akan dikurangi dengan tarif dasar rumus yang dihasilkan sebagai berikut.

Saldo = Saldo - Tarif Dasar

9. Proses pada tahap ini yaitu saldo yang dihasilkan setelah dikurangi tarif dasar atau dikurangi dengan pulsa.

10. Pada proses ini terjadi apabila jarak yang dihasilkan melebihi jarak minimum kemudian jarak yang dihasilkan akan dikurangi terlebih dahulu dengan jarak minimum untuk menghasilkan jarak lebih rumus yang dihasilkan sebagai berikut. Jarak Lebih = Jarak - Jarak Minimum

11. Jarak lebih akan dicek apakah melebihi atau sama dengan jarak hitung, jika kondisinya seperti itu akan menghasilkan rumus sebagai berikut.

Jarak Lebih = Jarak Lebih - Jarak Hitung

Kemudian dilanjutkan dengan pengurangan saldo dengan rumus sebagai berikut.

Saldo $=$ Saldo - Pulsa

12. Rumus tersebut dilakukan berulang kali sehingga jarak lebih tidak < dari jarak hitung. Apabila kondisi jarak lebih tidak melebihi atau sama dengan jarak hitung, saldo tidak akan berkurang lagi dan menghasilkan tarif yang sebenarnya 


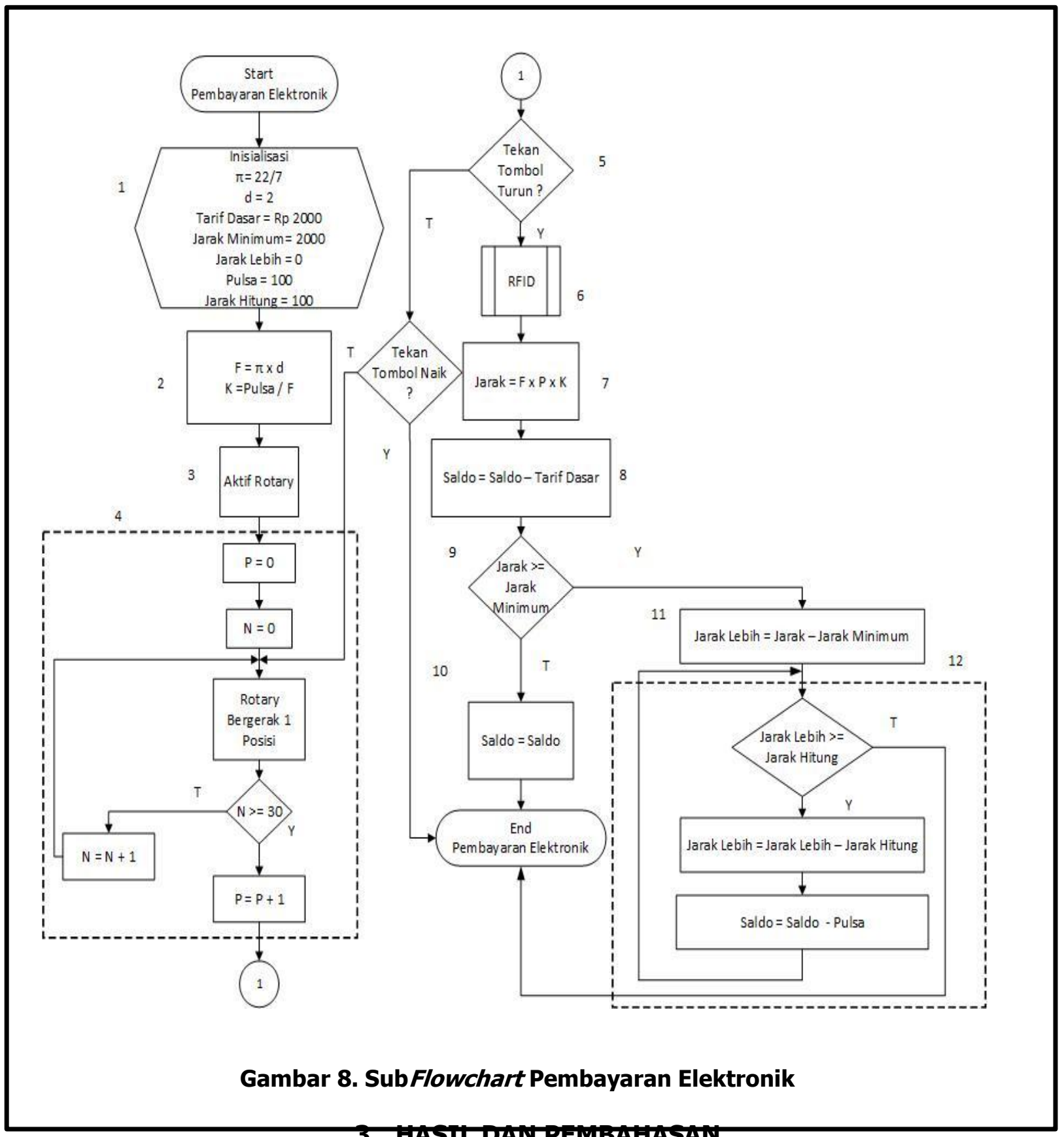

3. HASIL DAIN PEIMBATASAIV

Pada Gambar 9 terdapat arduino uno yang sudah dihubungkan pada ethernet shield yang dihubungkan menggunakan kabel jumper male to male pada $R F I D$ reader melalui project board, dimana pada saat sistem dijalankan RFID tag di tap pada RFID reader jenis RC522, $\angle C D$ dihubungkan dengan I2C yang berada dibawahnya untuk menampilkan hasil tarif dan id dari sistem yang dijalankan. Sementara rotary encoder $k y-040$ yang sudah dilengkapi dengan roda terhubung pada arduino uno menggunakan kabel jumper male to female. Terdapat 2 button dan 2 resistor dimana resistor digunakan untuk membuat button dapat berfungsi button pertama digunakan untuk inisiliasi dari penumpang yang akan menggunakan sistem pada saat naik, button kedua digunakan untuk pengguna pada saat turun atau keluar dari sistem. 


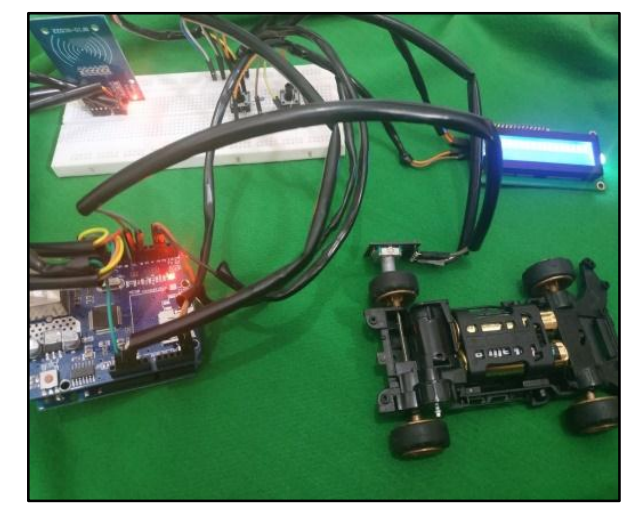

Gambar 9. Implementasi Sistem Perangkat Keras Pembayaran Elektronik

Berikut ini pada Gambar 10 merupakan alur pengujian fungsionalitas yang dilakukan terhadap sistem.

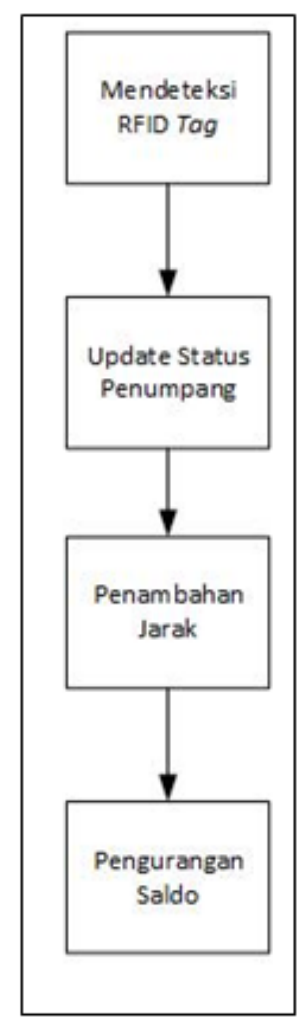

Gambar 10. Pengujian Sistem Fungsionalitas

Berikut merupakan hasil skenario pengujian berdasarkan alur pada Gambar 10 :

1. Pada Gambar 11 terdapat hasil dari pengujian RFID Tag.

2. Pada Gambar 12 terdapat hasil dari pengujian update status penumpang

3. Pada Gambar 13 terdapat hasil dari penambahan jarak.

4. Pada Gambar 14 terdapat hasil dari pengurangan saldo.

Pada Gambar 11 terdapat hasil dari proses pendeteksian RFID Tag dengan cara ditapkan pada RFID Reader. Hasil yang didapat adalah sistem dapat mendapatkan no UID dan menampilkannya pada serial monitor. 




Gambar 11. Pengujian Mendeteksi RFID Tag

Pada Gambar 12 terdapat hasil dari status penumpang yang terdapat pada database yang berubah saat tap pertama. Tap pertama dilakukan saat penumpang naik ke dalam kendaraan umum tersebut dengan menggunakan RFID tag yang di tap di RFID reader.

Pada Gambar 13 terdapat hasil dari sistem yang dapat menambahkan jarak berdasarkan rotary encoder yang diputar. Dimana rotary encoder tersebut digunakan untuk mengetahui arah putaran roda yang mana dapat menghasilkan output berupa jarak, sehingga tarif yang keluar sesuai dengan jarak tempuh yang dilalui angkot.

Pada Gambar 14 terdapat hasil dari sistem yang dapat menambahkan jarak berdasarkan rotary encoder yang diputar. Dimana rotary encoder tersebut digunakan untuk mengetahui arah putaran roda yang mana dapat menghasilkan output berupa jarak, sehingga tarif yang keluar sesuai dengan jarak tempuh yang dilalui angkot. 


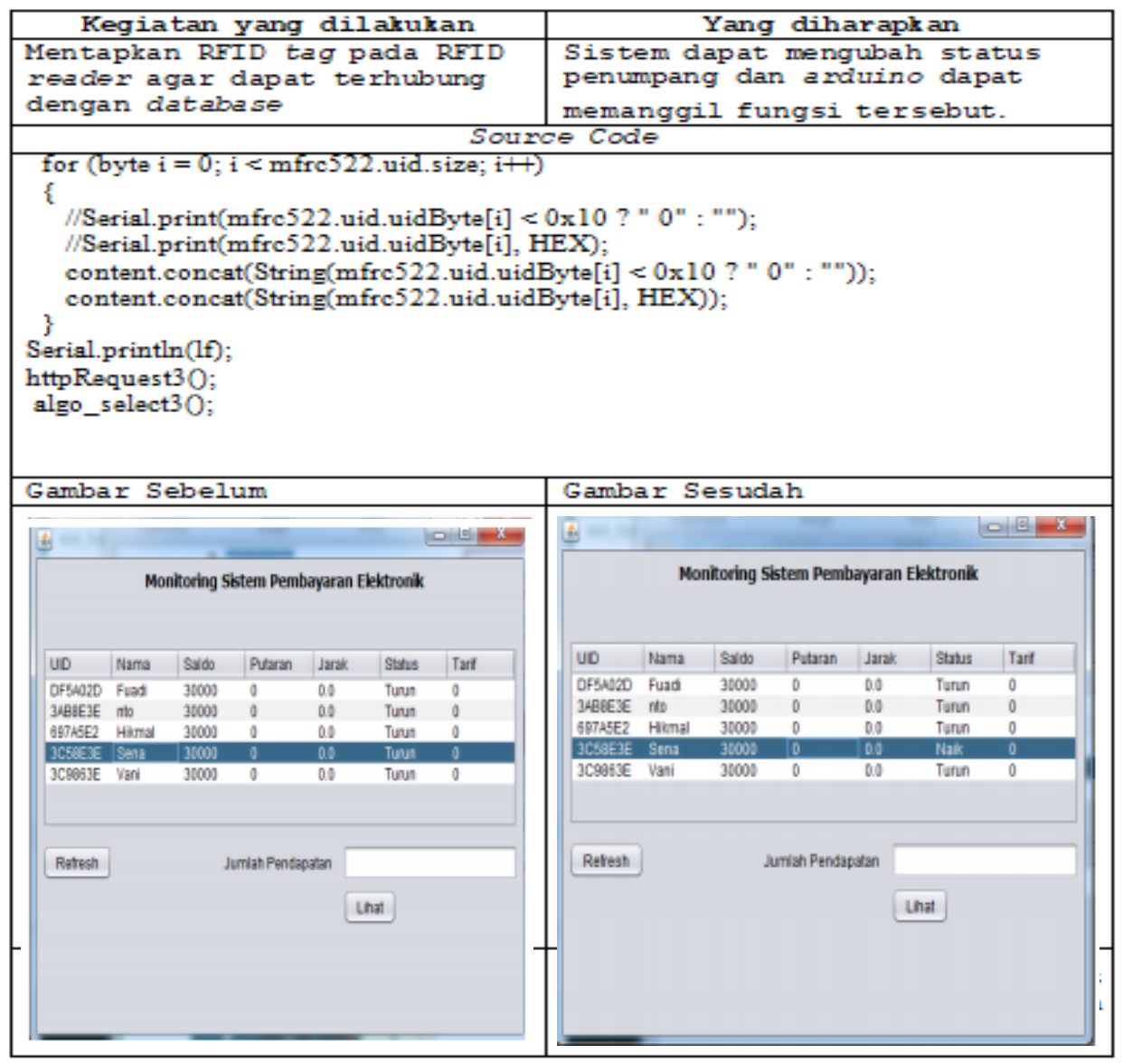

Gambar 12. Pengujian Update Status Penumpang

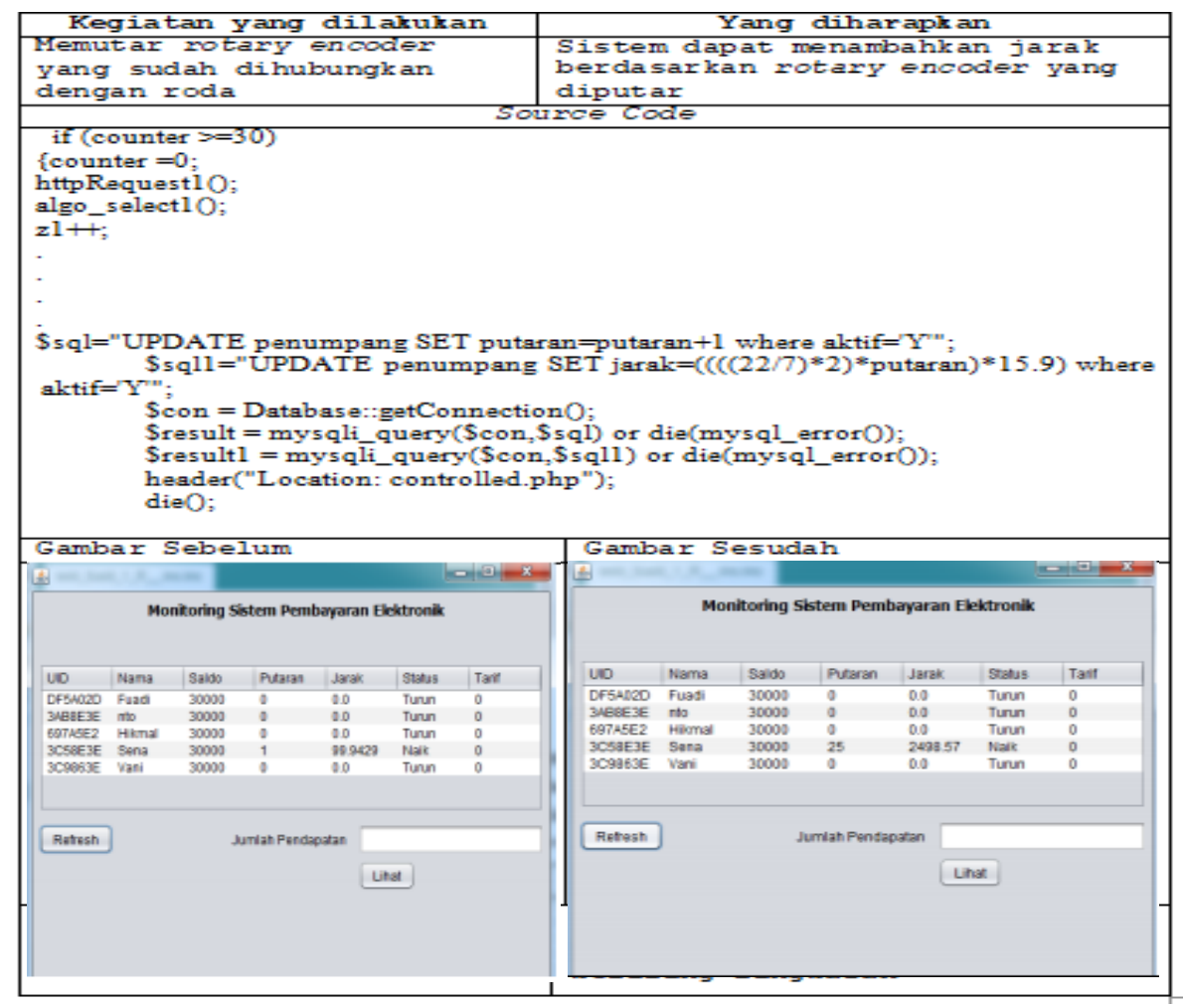

Gambar 13. Pengujian Penambahan Jarak 


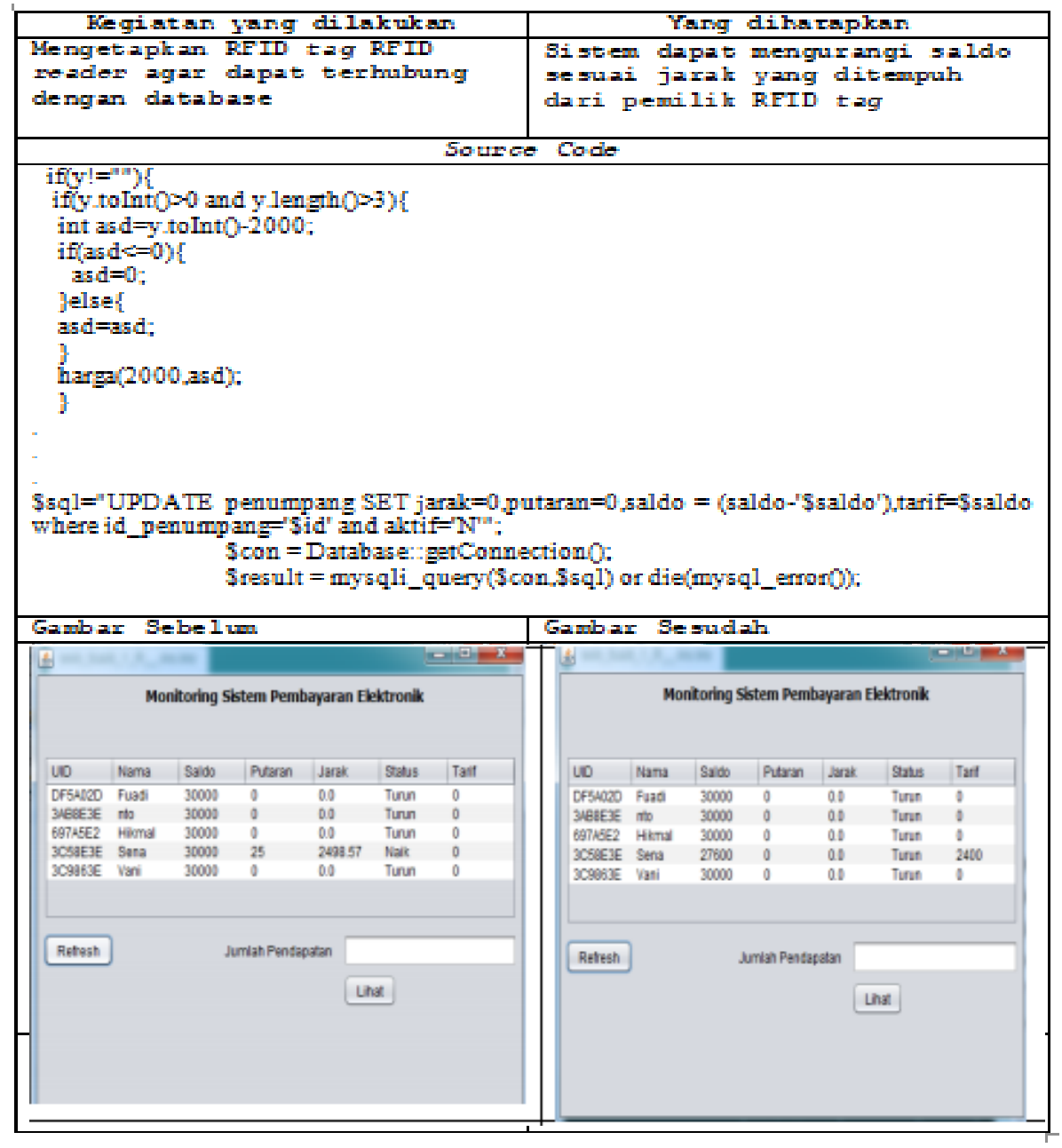

\section{Gambar 14. Pengujian Pengurangan Saldo}

Berdasarkan hasil pengujian sistem, pada sistem secara fungsional mengeluarkan hasil yang diharapkan, dimana UID dari RFID tag dapat terbaca dan mengupdate status pengguna pada database untuk menghitung jarak yang memanfaatkan putaran roda yang dihasilkan rotary encoder dan mengurangi saldo sesuai dengan skenario yang dibuat yaitu saldo bertambah Rp 100 dari tarif dasar Rp.2000 setelah mencapai jarak 2000 m dengan kelipatan 100 m selanjutnya.

\section{KESIMPULAN}

Sistem pembayaran elektronik dibangun dengan memanfaatkan $R F I D$ tag, $R F I D$ reader dan rotary encoder. Jumlah putaran roda dan ID yang didapatkan dari RFID tag tersebut diproses menggunakan perhitungan jumlah putaran roda yang diperoleh yang diprogram untuk menghasilkan jarak yang ditempuh yang dikonversikan dengan tarif sesuai jarak yang ditempuh. Berdasarkan pengujian sistem, UID penumpang dapat diketahui dengan menggunakan RFID tag pada saat proses tapping. Pada saat rotary encoder bergerak, jarak mulai bertambah dengan memanfaatkan putaran roda dimana jarak yang diperoleh diekuivalensikan sehingga mendapatkan jarak sebenarnya untuk selanjutnya dilakukan perhitungan tarif berdasarkan perhitungan yang ditetapkan mengikuti standar pengelola trayek umum. 


\section{DAFTAR RUJUKAN}

Ardiansyah, M. D., \& Rohman, F. (2019). Implementasi dan Analisis Kendali Kecepatan Motor BLDC $1 \mathrm{KW}$ Menggunakan Algoritma PID. Jurnal ELTEK.

Dejan. (2016). Tutorials Arduino Rotary Encoder Works Use Arduino. Diambil kembali dari https://howtomechatronics.com/tutorials/arduino/rotary-encoder-works-use-arduino/

Djahi, H. J., Doo, S. Y., \& Nuga, A. M. (2019). Rancang Bangun Robot Mobil dengan Sistem Navigasi Berbasis Odometry Menggunakan Rotary Encoder. Jurnal Media Elektro.

Jauhariah, S. W., Virgono, A., \& Sunarya, U. (2016). Perancangan Sistem Pengendali dan Monitoring Kecelakaan Mobil Berbasis Vehicular Ad Hoc Network (Vanet) Menggunakan Sensor Limit Switch dan Rotary Encoder.

Kuswidiyanto, A. (2018). Sistem Pengukuran dan Pemotongan Kertas Otomatis Menggunakan Incremental Rotary Encoder Berbasis PLC Omron. Universitas Sanata Dharma.

Olla, P. K. (2016). Pemanfaatan Teknologi RFID (Radio Frequency Identification) dalam Layanan Registrasi Rekam Medis.

Raj, A. (2018). Interfacing Rotary Encoder With Arduino . Diambil kembali dari https://curcuitdigest.com/microcontroller-projects/interfacing-rotary-encoder-witharduino/.

Saputra, H. M., Pambudi, T. A., \& Subagjo, D. G. (2016). Rancang Bangun Umpan Balik Eksternal untuk Kendali Sudut Motor Sevo Berbasis Arduino. Jurnal Teknologi Bahan dan Barang Teknik.

Utomo, S. A., Utomo, D., \& Yohanes, B. W. (2016). Sistem E-Money Berbasis Contactless Smart Card dengan Teknologi RFID.

Wiharja, U., \& Herlambang, G. (2019). Sistem Pengendali Kecepatan Putar Motor DC dengan Arduino Berbasis Labview. Jurnal IImiah Elektrokrisna. 